\title{
Interrupted Aortic Arch
}

National Cancer Institute

\section{Source}

National Cancer Institute. Interrupted Aortic Arch. NCI Thesaurus. Code C98958.

A rare congenital cardiovascular disorder characterized by the presence of a gap

between the ascending and descending portions of the thoracic aorta. This disorder is

often associated with ventricular septal defect, ductus arteriosus, or truncus arteriosus. 